\title{
EL OBISPO Y SUS ROLES PÚBLICOS EN LA GALIA MEROVINGIA; DESIGNACIÓN, FUNCIONES Y SU ALCANCE EN LOS SIGLOS VI Y VII D.C.
}

\section{THE PUBLIC ROLE OF BISHOPS IN THE MEROVINGIAN GAUL; APPOINTMENT, FUNCTIONS AND SCOPE IN THE VI AND VII CENTURIES A.D.}

Fernando C. Ruchesi

CONICET

Resumen: El siglo V de nuestra era es conocido por la alteración de las estructuras político-administrativas del imperio romano. A lo largo de este período, diversos pueblos bárbaros migraron a los territorios que formaban parte del imperio. Entre dichos pueblos se encontraba el de los francos merovingios, el cual se asentó en el norte de la Galia. En este contexto, la figura del obispo adquirió gran importancia en el territorio de la Galia, al punto de llevar a cabo funciones que anteriormente desempeñaban gobernadores romanos.

Palabras clave: Obispos; Merovingios; Galia
Abstract: The fifth century A.D. is known because of the alteration of the administrative and political structures of the Roman Empire. During this period, diverse barbarian peoples migrated into the territories of the empire. Among these peoples were the Merovingian Franks, who settled in northern Gaul. In this context the figure of the bishop became very important in the territory of Gaul, to the point of performing functions which previously were held by roman governors.

Keywords: Bishops; Merovingians; Gaul 


\section{Introducción}

El siglo V de nuestra era constituyó una etapa de turbulentos cambios para las estructuras político-administrativas del Imperio Romano de Occidente. Con el colapso de dichas estructuras y a raíz del asentamiento de pueblos bárbaros de origen germánico en estos territorios, comenzó el surgimiento de los primeros reinos post-romanos. Hacia el último cuarto del siglo V, el territorio de la Galia presentaba un mosaico de diversas culturas: la aristocracia galo-romana en el sur, los visigodos asentados en el sudeste y los francos en el norte. Las relaciones que se establecieron entre estos grupos, junto con las campañas expansionistas de los francos, fueron facilitando la conformación de una nueva sociedad. En este contexto, la figura del obispo comenzó a impregnarse de una importancia sin igual hasta el momento, en lo que se refiere a la administración de las cosas terrenales y espirituales.

El objetivo de este escrito es mostrar cómo confluían atribuciones de carácter civil y religioso en la figura del obispo en la Francia merovingia, entre los siglos V al VII d.C., recurriendo para ello al análisis de algunas de las obras representativas de ese período, tales como los Decem Libri Historiarum y Libri de virtutibus sancti Martini episcopi de Gregorio de Tours y el Chronicon de Fredegario.

\section{Los obispos en los siglos IV al VI: sus antecedentes y su función pública}

Como es sabido, con la tolerancia hacia el cristianismo impuesta por el emperador Constantino en 313, se generaron numerosos cambios. Esta etapa se caracterizó por el hecho de que la Iglesia fue adquiriendo cada vez más importancia en la vida pública del Imperio ${ }^{1}$. Esta nueva espiritualidad, al ser adoptada por la mayoría de los emperadores que sucedieron a Constantino, dio lugar a un enorme incremento en el número de conversiones, las cuales alcanzaron

\footnotetext{
${ }^{1}$ Es preciso además tener en cuenta que, durante la Antigüedad Tardía, la Iglesia también se fue consolidando política y económicamente. Por ejemplo, el período que se abre a partir del siglo IV constituye la etapa en la que esta institución de la fe conjuntamente se va transformando en una institución terrateniente por excelencia, a través de las concesiones imperiales, donaciones piadosas y el oportunismo directo. Este rasgo estará presente de manera muy marcada en las relaciones sociales y económicas. Peter SARRIS, "Lay Hostility to Holy Men and the Church", en Peter SARRIS, Matthew DAL SANTO \& Phil BOOTH (Ed.). An Age of Saints? Power, Conflict and Dissent in Early Medieval Christianity, Leiden, Brill, 2011, p. 2-3.
} 
a manifestarse, como era de esperar, en la clase curial y en la aristocracia de origen senatorial. De esta manera, el cristianismo se fue transformando en un fenómeno de gran magnitud social a lo largo del siglo IV, siendo el obispo su representante urbano de mayor jerarquía e importancia. Para entonces, su posición ya le permitía contar con gran influencia y responsabilidad ${ }^{2}$, además de que comenzó a acaparar funciones pertenecientes al ámbito público. ${ }^{3}$

Sin embargo, este proceso fue lento y estuvo marcado por dificultades. En este sentido, durante los siglos IV al VI, la cristiandad se caracterizó por ser, en general, un fenómeno de carácter urbano. En este espacio, el obispo, como representante de la fe y administrador de las cosas de la Iglesia, contaba con diversas funciones que siempre -o en la mayoría de los casos- se referían solamente a ese ámbito de la ciudad. Claro está, esto dificultaba la expansión del cristianismo en las áreas rurales. En ese entorno rural, además, continuaba reinando el sentido pre-cristiano de lo sagrado, es decir, un paisaje espiritual antiguo y pre-cristiano, como afirma Peter Brown. ${ }^{4}$

\section{Orígenes sociales de los obispos de la Galia. La elección episcopal}

Si bien la función episcopal es de carácter eclesiástico, por lo general, no eran eclesiásticos quienes obtenían la misma. Desde los tiempos tardoimperiales, los obispos eran elegidos entre candidatos que provenían de las familias aristocráticas de origen romano. Estas familias, como bien sabemos, se esforzaban en demostrar sus orígenes romanos, como así también en practicar y conservar aquellos rasgos culturales propios de su clase (tales como el estudio de las letras latinas ${ }^{5}$.

\footnotetext{
2 Claudia RAPP, Holy Bishops in Late Antiquity; The Nature of Christian Leadership in an age of Transition, Los Angeles, University of California Press, 2005, p. 167.

${ }^{3}$ Por lo general, la mayoría de los historiadores afirman que, durante el Imperio Romano tardío, las esferas del poder civil y religioso eran percibidas como dos polos separados. Sin embargo, Rapp estima que es más fructífero concebir tales esferas de autoridad como los extremos opuestos de una escala móvil. En dicha escala, cada individuo, ya sea de origen político o religioso, poseía su propio lugar dependiendo de su conducta personal y del papel que desempeñaba en la sociedad.

4 Peter BROWN, Authority and the Sacred; Aspects of the Christianisation of the Roman World, Cambridge, Cambridge Univeristy Press, 1995, p. 4.

${ }^{5}$ Los aristócratas civiles romanos se preciaban de conocer la obra de Virgilio de memoria (en Occidente) y la de Homero (en Oriente). Para más información, ver Chris WICKHAM, "La Sociedad", en: Rosamund MCKITTERICK, La Alta Edad Media, Barcelona, Crítica, 2002, p. 71.
}

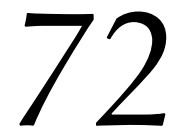


Debemos tener en cuenta, además, que los oficios públicos eran muy codiciados por los miembros de las familias aristocráticas en el contexto del Imperio Romano tardío, con lo cual se generaba una competición salvaje entre sus miembros ${ }^{6}$. En este sentido, la dignidad episcopal representaba una alternativa muy viable para muchos aristócratas que aspiraban a obtener un cargo público. De tal manera, muchos jóvenes provenientes de este estrato social lograron constituir el sector más importante -numéricamente hablando- del naciente episcopado. ${ }^{7}$

Pero los obispos de la Francia merovingia no sólo se destacaban por sus orígenes latinos sino también por su formación. En la mayoría de los casos, antes de ocupar el cargo, estos individuos se habían desempeñado en la administración civil $^{8}$. Muchos de ellos también habrían ejercido funciones condales ${ }^{9}$. Al ocuparse de tales actividades, les era posible obtener una importante experiencia como administradores, la cual era luego empleada para llevar adelante las funciones propias de la administración episcopal.

Respecto a este apartado, en los Libri Historiarum X, de Gregorio de Tours, encontramos un caso particular, que nos ilustra sobre la carrera civil de un duque previa al episcopado. En el pasaje, un muchacho es enviado por el rey Gontrán para preguntar sobre su futuro a una mujer vidente. A su regreso, la respuesta que trajo consigo fue que el rey Chilperico moriría ese año y el rey Meroveo excluiría a sus hermanos y tomaría todo el reino. Tras ello,

Tu vero ducatum totius regni eius annis quinque tenebis. Sexto vero anno in una civitatum, quae super Legeris alveum sita est, in dextera eius parte,

\footnotetext{
${ }^{6}$ Hasta inicios del siglo VII, los aristócratas de origen romano controlaban obispados situados en importantes ciudades del norte de la Galia tales como Tréveris, Colonia y Metz. Los aristócratas merovingios pasarían a luchar contra los romanos por el control de estos y otros obispados. Para más información, véase: Raymond VAN DAM, "Merovingian Gaul and the Frankish Conquests", en Paul FOURACRE (ed.), The New Cambridge Medieval History, Volume I c.500-c.700, Cambridge, Cambridge University Press, 2008, p. 217.

${ }^{7}$ Claudia RAPP, op. cit., p. 168.

${ }^{8}$ Chris Wickham afirma que existía una relación muy estrecha entre la condición aristocrática y la ocupación de un cargo imperial. Con el paso del tiempo, la jerarquía eclesiástica se convirtió en una codiciada meta para muchas familias destacadas, debido también a que la misma estaba exenta de impuestos.

${ }^{9}$ Con la aparición del obispo como administrador civil y organizador de los espacios civiles y religiosos en la Galia, el conde fue perdiendo importancia como funcionario público. Además, su reputación también fue decreciendo en favor de la del obispo. En: Patrick GEARY, Before France and Germany. The creation and transformation of the Merovingian World, Oxford y Nueva York, Oxford University Press, 1988, p. 131-132.
}

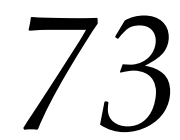


favente populo, episcopatus gratiam adipiscis ac senes et plenus dierum ab hoc mundo migrabis. ${ }^{10}$

De tal manera, el texto manifiesta que, para la época, no resultaba extraño que un personaje proveniente del ámbito civil llegase a ocupar el cargo de obispo si contaba con los vínculos necesarios.

Ahora bien, no existe ninguna referencia canónica o legal que especifique los antecedentes sociales y económicos requeridos para obtener la dignidad episcopal ${ }^{11}$. Es decir, aquellos cuyos orígenes sociales no se encontraban entre los más privilegiados y destacados, en teoría no contaban con obstáculos para ser seleccionados y desempeñarse en el clero. Si bien era común que los obispos proviniesen de familias aristocráticas, también llegaron a obtener la dignidad episcopal personas que se habrían desempeñado como artesanos y trabajadores manuales. ${ }^{12}$

Una característica peculiar que fue adquiriendo esta dignidad eclesiástica, durante las primeras décadas de vida de la monarquía merovingia, fue la elección episcopal directa por parte de los reyes. En los citados Libri Historiarum encontramos varios ejemplos interesantes que pueden ayudarnos a comprender mejor esta situación. En uno de ellos, el rey Chilperico, al enterarse de los males que el conde Leudast había hecho a las iglesias de Tours, envió a Ansoald a aquella ciudad para elevar como obispo a Eunomio. ${ }^{13}$ En otro ejemplo, se lee lo siguiente:

Promotus vero, qui in Dunense castro ordinante Sigybertho rege episcopus fuerat institutus et post mortem regis amotus fuerat, eo quod castrum illud

10 GREGORIO DE TOURS, Libri Historiarum X, MGH SRM I, I, ed. Bruno Kursch y Wilhelm Levison, Hanover, Hahn, 1937-51, V.14.

${ }^{11}$ No todos los obispos provenían de la administración civil. Algunos prelados lograron ascender a partir del monacato. En estos casos -los cuales eran escasos-, la posición de archidiácono -por aquel entonces, muy codiciada por los miembros del monacato- era ideal para lograr alcanzar la dignidad episcopal. El archidiácono, además de contar experiencia en lo que respecta a la administración de gobierno, también poseía la formación eclesiástica necesaria y requerida para llevar adelante estas funciones.

${ }^{12}$ Claudia RAPP, op. cit.,p. 173.

13 "Audiens autem Chilpericus omnis mala, quae faciebat Leudastis ecclesiis Toronicis vel omni populo, Ansovaldum illue dirigit. Qui veniens ad festivitatem sancti Martini, data nobis populo optionem, Eunomius in comitatum erigitur." En: GREGORIO DE TOURS, op. cit., V.47. 
esset diocisis Carnotena -contra quem ita iudicium latum fuerat, ut praesbiterii tantum officium fungeretur-... ${ }^{14}$

En otras palabras, Promotus, un aristócrata que habría sido nombrado obispo por el rey Sigiberto, dejó de serlo tras la muerte de este soberano. Además, fue acusado y sólo se le permitieron ejercer funciones sacerdotales. Este ejemplo también nos muestra una relación entre las peculiaridades de las atribuciones episcopales en este período respecto de las características de las funciones civiles. En este caso, se trata de un conflicto de carácter político en el que dos facciones competían por hacerse con el poder. El fragmento continúa de la siguiente manera:

...accessit ad regem, depraecans, ut ordinationem episcopatus in antedicto castro reciperet. Sed, obsistente Pappolo Carnotenae urbis episcopo ac dicente, quia: 'Diocisis mea est', ostendente praesertim iudicium episcoporum, nihil aliud potuit obtenere cum rege, nisi ea quae sub ipsius castri termino propria habebat reciperit, in qua cum genetrice adhuc superstite moraretur. 15

Como vemos, el retorno de Promotus a esa vida sacerdotal no fue sencillo. El obispo de Chartres, Pappalus, no le permitió regresar a la parroquia, señalando que ésta era suya y que la decisión fue tomada por el cuerpo de obispos. En este caso, vemos una contradicción. La misma se hace manifiesta en el hecho de que el obispo de Chartres estaba rechazando la elección directa que había realizado el monarca merovingio. De esta manera, si bien aquellos que deseaban alcanzar la dignidad episcopal requerían determinados elementos para llegar a ser consagrados -como la formación y la experiencia en la administración- algunas veces, dependiendo del contexto, se pasaban por alto estos mecanismos de selección. Además, el período que siguió a la muerte de Sigiberto estuvo marcado por la guerra civil desatada por su medio hermano Chilperico, que se anexionó Austrasia ${ }^{16}$. Más allá de eso, Gregorio de Tours deseaba mostrar, con este pasaje, cómo operaban en realidad los mecanismos políticos involucrados en la elección de los obispos. Si tenemos en cuenta que el rey Sigiberto murió y que los demás

\footnotetext{
${ }^{14}$ GREGORIO DE TOURS, op. cit., VII.17.

15 Ibidem.

${ }^{16}$ Ian WOOD, The Merovingian Kingdoms 450-751, Nueva York, Longman, 1994, p. 89.
} 
prelados del reino estaban al tanto de la posible invasión de Chilperico, estos últimos habrían operado velozmente a fin de aprovechar el pequeño vacío de poder presente tras la muerte del rey para cumplir con sus propias ambiciones políticas, siendo éste un ejemplo característico de tal situación. ${ }^{17}$

En otro episodio, el rey Clotario se encontraba orando en una iglesia. Al enterarse de esto, el beato Domnolus se dirigió a ese templo para hacer llegar al monarca una sugerencia acerca de sus intenciones:

Migrante autem Avenniensis civitatis pontifice istum illuc dare deliberaverat. Sed beatus Domnolus haec audiens, ad basilicam sancti Martini antistitis, ubi tunc Chlotharius rex ad oratiounem venerat, accessit, et nocte tota in vigiliis excubans, per priores qui aderant regi suggessionem intulit, ut non quasi captivus ab eius elongaretur aspectu, nec permitteret, simplicitatem illius inter senatores sophisticos ac iudices philosophicos fatigari, adserens, hunc locum humilitatis sibi esse potius quam honoris. Ad haec rex annuens, migrante Innocentio Cinomanorum episcopo, ipsum ecclesiae illi antistitem destinavit. ${ }^{18}$

Como podemos apreciar, la fortuna lo acompañó para lograr convencer al monarca y Domnolus se hizo con el cargo. Sin embargo, luego de veintidós años de servicio, éste tomó la decisión de proponer al soberano merovingio un candidato para su reemplazo en la sede, lo que no fue del agrado del monarca:

Qui post XXII episcopati annos, dum se cerneret morbo regio calculoque gravissime fatigari, Theodulfum abbatem in loco suo praeelegit. Cuius assensum rex praebuit voluntatem, sed non multum post tempus, mutata sentantia, in Badegisilum domus regiae maiorem transfertur electio. Qui tonsuratus, gradus quos clerici sortiuntur ascendens, post quadraginta diebus, migrante sacerdote, successit. ${ }^{19}$

Vemos aquí que el rey cambió de opinión y eligió a Badegisil, su mayordomo de palacio, lo cual es otro ejemplo de que la decisión, en última instancia, recaía en la figura del monarca.

Otro caso similar es el de Burgundio, el joven sobrino de Félix, obispo de Nantes. Este último, afectado por la peste bubónica, suplicó a los obispos de los territorios vecinos que lo ayudasen proporcionándole el consenso necesario para

\footnotetext{
17 Patrick GEARY, op. cit., P. 120.

${ }^{18}$ GREGORIO DE TOURS, op. cit., VI.9.

${ }^{19}$ Ibidem.
} 
que su sobrino pudiera recibir la dignidad episcopal. Sin embargo, tras el rechazo por parte del mismo Gregorio de Tours a esta medida y su posterior consejo para Burgundio ${ }^{20}$, el rey finalmente optó por elegir a Nonnichius, quien era el primo del obispo Félix, luego de que éste último pereciera debido a la mencionada plaga.

Esta situación nos resulta particular debido a que, en ella, Gregorio hace referencia de los cánones. Afirma que, según los mismos, se podría beneficiar de la dignidad episcopal solamente aquél que cumplía con ciertos requisitos y se dedicaba a la labor propia de la Iglesia. El candidato, además, debía atravesar por determinadas posiciones en el escalafón propio de la institución religiosa. Pero, como hemos podido apreciar, en este caso fue nuevamente el monarca merovingio el que tuvo la última palabra con respecto a la designación.

En el libro sexto de las historias de Gregorio, más precisamente en el capítulo 46, Gregorio trata sobre la muerte del rey Chilperico I de Neustria. En esta ocasión, aprovecha el momento para comentar y caracterizar tanto al difunto rey como a su reinado. El autor de la obra lanza así duras críticas. En una de ellas afirma que "In cuius tempore pauci quodammodo episcopatum clerici meruerunt"21, frase a partir de la cual puede ser inferida una severa acusación..$^{22}$

Sin embargo, en el mismo pasaje, el obispo de Tours cita las palabras del rey fallecido:

Aiebat enim plerumque: 'Ecce pauper remansit fiscus noster, ecce divitiae nostrae ad eclesias sunt translatae; nulli penitus nisi soli episcopi regnant; periet honor noster et translatus est ad episcopus civitatum' ${ }^{23}$

En este caso, el autor pone en boca del difunto Chilperico un par de duras afirmaciones. En la primera de ellas, nulli penitus nisi soli episcopi regnant (ya sea que la haya dicho o no Chilperico), sorprende el hecho de que Gregorio reconocía que los obispos se encargaban de tareas algo alejadas de la labor pastoral. En la

\footnotetext{
${ }^{20}$ Con respecto a este rechazo, Gregorio escribió: “Quod ego abnui, quia canonibus non congruere cognovi. Consilium tamen praebui dicens: «Habemus scriptum in canonibus, fili, non posse quemquam ad episcopatum accedere, nisi prius ecclesiasticus gradus regulariter sortiatur. Tu ergo, dilectissime, revertere illuc et pete, ut ipse te qui elegit debeat tonsorare. Cumque presbiterii honorem acciperis, ad ecclesiam adsiduus esto; et cum eum Deus migrare voluerit, tunc tu facile episcopale gradum ascendes».". En: GREGORIO DE TOURS, op. cit., VI.15.

${ }^{21}$ Op. cit., VI.46.

${ }^{22}$ No debe sorprendernos que el obispo de Tours escriba de esta manera sobre la muerte de un rey que no estuvo muy de acuerdo con las políticas de la Iglesia. Ian WOOD, op. cit., P. 66.

${ }^{23}$ Ibidem.
}

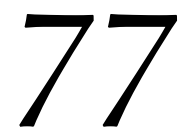


segunda, periet honor noster et translatus est ad episcopus civitatum, se queja de que las funciones del gobierno y la administración civil desaparecerían y, además, pasarán a ser transferidas a los obispos de las ciudades para que éstos las llevasen a cabo. Ambas constituyen interpretaciones y consideraciones acerca de las características que poseía la dignidad episcopal en el siglo VI, siendo lo más importante, en este caso, el hecho de que estas afirmaciones hayan sido recogidas por un miembro del episcopado.

En síntesis, si bien la dignidad era de origen eclesiástico, solamente podía desempeñarse como obispo aquél que fuera aprobado en última instancia por el rey $^{24}$. De esta manera, a partir de todo lo que hemos expuesto hasta el momento, podemos afirmar que los reyes merovingios, al menos durante el siglo VI, ejercieron una influencia considerable en la designación de los obispos ${ }^{25}$. Esta costumbre se extendió e incluso reforzó durante el período carolingio.

\section{Las funciones del obispo}

El dramático contexto político administrativo que presentaba la Galia durante el siglo $\mathrm{V}$ sentó las condiciones para la consolidación de las atribuciones de los prelados. Por un lado, la llegada de los francos al norte de esa región dio origen a una serie de cambios políticos, económicos y administrativos. Entre estos se destacaron la gradual absorción político-administrativa de los territorios de la Galia, que anteriormente pertenecían a Roma, al dominio merovingio.

En este contexto difícil -en el que las autoridades romanas dejaron a su suerte numerosos territorios a raíz de las luchas internas y las migraciones germánicas $^{26}$ - muchas de las atribuciones que poseían los obispos cobraron una mayor importancia. Se trataba de competencias tales como la preocupación por los pobres, la distribución de las limosnas, la responsabilidad por las viudas y huérfanos, como así también la visita de aquellos que estaban en prisión. Dichas

\footnotetext{
${ }^{24}$ Con respecto a la aprobación del rey, se trató de una nueva modalidad de elección episcopal que habría sido introducida en el mismo momento en que la monarquía franca se consolidó con Clovis. Patrick GEARY, op. cit., p. 133.

${ }^{25}$ Sin embargo, como afirma Van Dam, a menudo los obispos no permitirían tal abuso de poder por parte de los reyes, recordándoles que eran ellos quienes tenían en sus manos el acceso al poder milagroso de los santos. En: Raymond VAN DAM, op. cit., p. 215.

26 Guy HALSALL, Barbarian Migrations and the Roman West 376-568, Cambridge, Cambridge University Press, 2007, pp. 257-283.
} 
competencias fueron así reforzadas en cuanto a su significación en un proceso que se caracterizó por el vacío de poder creado por el Imperio Romano.

En dicho vacío de poder, los prelados comenzaron a cumplir determinadas tareas públicas que anteriormente se encontraban en manos de funcionarios civiles romanos como los defensores ${ }^{27}$. Entre tales funciones se encontraban las de defender jurídicamente a los pobres ${ }^{28}$. Además, eran los encargados de construir y mantener las murallas, los canales y demás obras de carácter público relacionadas con la vida cotidiana de la comunidad. Como podemos inferir, durante este período los obispos se ocupaban de las funciones típicas que atañían a un gobernador o a un administrador civil.

Un punto a favor con que contaban los prelados era la sólida formación administrativa. De esta manera, numerosas tierras y jurisdicciones terminaron siendo controladas por ellos. Dicha acumulación captó la atención de los monarcas merovingios, quienes buscaron obtener ingresos aplicando impuestos a las propiedades y jurisdicciones bajo mandato episcopal. Sin embargo, existieron obispos que se opusieron firmemente a estas medidas. He aquí un ejemplo de tal situación:

Denique Chlothacharius rex indixerat, ut omnes eclesiae regni sui tertiam partem fructuum fisco dissolverent. Quod, licet inviti, cum omnes episcopi consensissent, atque subscripsissent, viriliter hoc beatus Iniuriosus respuens, subscribere dedignatus est, dicens: Si volueris res Dei tollere, Dominus regnum tuum velociter aufret, quia iniquum est, ut pauperes, quos tuo debes alere horreo, ab eorum stipe tua horrea repleantur. Et iratus contra regem nec valedicens abscessit. Tunc comotus rex, timens etiam virtutem beati Martini, misit post eum cum muneribus, veniam praecans et hoc quod fecerat damnans, simulque et rogans, ut pro se virtutem beati Martini antestites exoraret. ${ }^{29}$

Desde este caso podemos inferir diversas situaciones. Por un lado, cuando Gregorio describe a los obispos del reino como aceptando a "regañadientes" la decisión del monarca, está señalando claramente el repudio a una medida cuyo resultado puede interferir o ser contraria a los intereses de su clase. En segundo lugar, el discurso de Iniuriosus hace referencia al origen de los bienes de Dios que se hallan en las iglesias: los pobres. Desde esta perspectiva, su oposición al

\footnotetext{
${ }^{27}$ Ian WOOD, The Merovingian Kingdoms 450-751, Nueva York, Longman, 1994, p. 75.

${ }_{28}$ Robert FOSSIER, La Edad Media; 1. La formación del mundo medieval 350-950, Barcelona, Crítica, 1988, p. 53.
}

${ }^{29}$ GREGORIO DE TOURS, op.cit., IV.2.

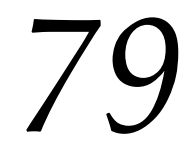


impuesto representa para Gregorio el justo y fiel administrador episcopal, el arquetipo en el cual deberían inspirarse los candidatos para convertirse en el buen obispo que ayuda a los devotos cristianos y los defiende de las duras imposiciones de la monarquía merovingia.

En numerosas ocasiones, además, los miembros del episcopado cumplían la función de consejeros para con los monarcas merovingios. En la obra de Gregorio, encontramos algunos ejemplos que pueden ilustrar mejor esta situación. En uno de ellos, el obispo Germanus recomendaba al rey Sigiberto no matar a su hermano Chilperico, si su propósito era tomar los pueblos y ciudades que se encontraban entre París y Ruan. ${ }^{30}$

En suma, en un cargo de origen eclesiástico se amalgamaban el espacio público civil y el espacio público religioso ${ }^{31}$. En esta confluencia, el aspecto eclesiástico estaría representado por las funciones por excelencia del obispo, que son las de defender y predicar la fe, ayudar a los pobres, ser el administrador de las cosas de Dios y dirigir la construcción de iglesias y organizarlas. El carácter político, por su parte, estaría presente en las funciones de naturaleza civil que el obispo debía desempeñar en la comunidad local. Tales atribuciones eran similares a las que realizaban administradores o gobernadores.

\section{Los obispos y el espacio espiritual}

Con respecto al ámbito espiritual, el obispo tenía en sus manos -entre muchas cosas- una función muy importante: el control de los lugares asociados con el culto de los santos ${ }^{32}$. Debido a que el proceso de canonización ni siquiera existía como tal durante esta etapa, la creación del culto dedicado a un santo dependía, entre muchas otras cosas, de dos factores. Por un lado, la existencia de

\footnotetext{
30 "...Illi vero haec audiens, misitque qui fratrem suum in supra memoratam civitatem obsederent, ipsi illuc properare deliberans. Cui sanctus Germanus episcopus dixit: 'Si abieris et fratrem tuum interficere nolueris, vivus et victur redis; sin autem aliut cogitaveris, morieris'.". En: GREGORIO DE TOURS, op. cit., IV.51

${ }^{31}$ Para Ramón Teja, el obispo es la creación más original del mundo antiguo en su etapa final y la que mejor la caracteriza, debido a que, en palabras del autor, “... según el punto de vista del observador, puede aparecer como un sacerdote, un político, un rétor, un jurista, un juez, pero el resultado final es una conjunción de todas ellas.". Véase: Ramón TEJA, Emperadores, Obispos, Monjes y Mujeres; Protagonistas del Cristianismo Antiguo, Madrid, Ed. Trotta S.A., 1999.

${ }^{32}$ Conforme a Patrick Geary, la tradición episcopal no sólo intentó asimilar para sí misma el poder de los santos sino que también buscó incorporar creencias populares en la tradición cristiana. Véase: Patrick GEARY, op. cit., p. 139.
} 
una congregación dispuesta a admitir que un lugar particular -por lo general, una tumba- estaba investida con poder espiritual. En segundo lugar, era necesario el reconocimiento oficial del sitio por parte de las autoridades de la Iglesia, siendo el obispo local su representante directo en este caso $^{33}$. Naturalmente, se trataba de una atribución de suma importancia teniendo en cuenta el contexto religioso de la época. En relación con esto, Dominique Iogna-Prat afirma que, en la Antigüedad tardía, la cristiandad se vinculó a aquellos lugares en los cuales la presencia de restos sagrados distinguía a esos sitios del conjunto de lugares comunes. En este sentido, la santidad de un sitio dependía, en gran medida, del grado de santidad que poseían las personas a las que dichos lugares fueron consagrados $^{34}$. En relación con el citado contexto de la Galia merovingia en el siglo VI, las obras de Gregorio de Tours ${ }^{35}$ presentan dos importantes lugares en los que se manifestaba el poder sagrado a través de los milagros: la iglesia consagrada a san Martín de Tours y la tumba del mismo santo. En cuanto al primero de tales sitios, en una ocasión, el duque Austrapius se refugió en la iglesia del patrono de Tours por temor a Chramnus. Éste ordenó que Austrapius permaneciera encerrado y que muriera de hambre. Sin embargo, el duque recibió una bebida de forma milagrosa y logró salvarse. Con el paso del tiempo, se convirtió en sacerdote. ${ }^{36}$

\footnotetext{
${ }^{33}$ Ian WOOD, op. cit., p. 74.

${ }_{34}$ Dominique IOGNA-PRAT, La Maison Dieu. Une histoire monumentale de l'Église au Moyen Âge, París, Seuil, 2006, p. 41-42.

${ }^{35}$ Además de los citados Libri Historiarum, véase: Liber de passione et virtutibus sancti Iuliani martyris y Libri I-IV de virtutibus sancti Martini episcopi. En: GREGORIO DE TOURS, Miracula et opera minora. Editio nova lucisope expressa, MGH SRM, I,II, ed. Bruno Krusch, Hannover, Hahn, 1885-1969.
}

36 "Tunc et Austrapius dux Chramnum metuens, in basilica sancti Martini confugit. Cui tali in tribulatione posito non defuit divinum auxilium. Nam cum Chramnus ita eum constringi iussit, ut nullus illi alimenta praebere praesumerit, et ita arcius custodiretur, ut nec aquam quidem ei aurire liceret, quo facilius conpulsus inaedia ipse sponte sua de basilicam sancta periturus exiret, accedens quidam vasculum illi cum aqua simevivo detulit ad putandum. Quo accepto, velociter iudex loci advolavit ereptumque de manu eius terra diffudit. Quod velox Dei ultio et beati antestetis virtus est subsecuta. Eam namque die iudex qua ista gesserat correptus a febre, nocte media expiravit, nec pervenit in crastino ad illam horam, qua in basilica sancti poculum de manu excusserat fugitivi. Post istud miraculum omnes ei poplentissime quae erant necessaria detulerunt. Redeunte autem in regnum suum rege Chlothario, magnus cum eo est habitus. Tempore vero eius ad clericatum accedens, apud Sellensim castrum, quod in Pectava habitur diocisi, episcopus ordenatur; futurum, ut, decedente Pientio antestite, qui tunc Pectavam regebat eclesiam, ipse succederet. Sed rex Charibertus in aliut vertit sententiam. Pascentius, qui tunc abba erat basilicae sancti Helari, ei succedit ex iussu regis Chariberthi, clamante Austrapio, sibi hunc redebere locum. Sed parum ei iactati profuere sermones. Ipse quoque regressus ad castrum suum, mota super se Theifalorum seditione, quos saepe gravaverat, lancea sauciatus crudiliter vitam finivit. Diocesses vero suas eclesia Pectava recipit.". GREGORIO DE TOURS, Libri Historiarum X, MGH SRM I, I, ed. Bruno Kursch y Wilhelm Levison, Hanover, Hahn, 1937-51, IV.18.

\section{1}


En otro ejemplo, el archidiácono de Bourges, Leonastis, tras quedarse ciego debido a la enfermedad de cataratas, visitó a varios médicos sin poder conseguir una cura. Solamente después de pasar varios meses orando en la iglesia de San Martín de Tours, su visión regresó. ${ }^{37}$

Por otra parte, la fe y la confianza que los contemporáneos del obispo Gregorio depositaban en el citado edificio eran tan grandes, que el mismo era considerado como un refugio para aquellos que buscaban huir de la autoridad civil por crímenes $\operatorname{cometidos}^{38}$. De la misma manera, este poder espiritual que rodeaba la iglesia de San Martín y sus cercanías también afectaba a sus posesiones $^{39}$, las cuales a menudo eran objeto de codicia por parte de algunos sacerdotes, según lo denuncia el mismo obispo Gregorio. ${ }^{40}$ El autor de los mencionados Libri de virtutibus sancti Martini episcopi, también fue protagonista de varios de estos milagros. En una ocasión, Gregorio fue afectado por una fuerte fiebre que lo debilitó. Creyendo que iba a morir, pidió ayuda a sus amigos para que lo acompañasen a la iglesia del santo de Tours, donde logró recuperarse. ${ }^{41}$

\footnotetext{
37 "Leonastis Biturigus archidiaconus, decedentibus cataractis, lumen caruit oculorum. Qui cum, per multos medicos ambulans, nihil omnio visionis recipere possit, accessit ad basilicam beati Martini, ubi per duos aut tres menses consistens et ieiunans assiduae, lumen ut reciperet flagitabat. Adveniente autem festivitate, clarificatis oculis cernere coepit; regressus quoque domum, vocato quodam Iudaeo, ventosas, quorum beneficio oculis lumen augeret, humeris superponit. Decedente quoque sangine, rursus in redeviva caecitate redigitur. Quod cum factum fuisset, rursum ad sanctum templum regressus est...". GREGORIO DE TOURS, op.cit., V.6.

38 "Post haec Merovechus, cum in custodia a patre reteneretur, tunsoratus est, mutataque veste, qua clericis uti mos est, presbiter ordenatur et ad monasterium Cinnomannicum qui vocatur aninsola dirigitur, ut ibi sacerdotali eruderetur regula. Haec audiens Gunthchramnus Boso, qui tunc in basilica sancti Martini, ut diximus, resedebat, misit Riculfum subdiaconum, ut ei consilium occulte praeberet expetendi ad basilicam sancti Martini. Qui cum abisset, ab alia parte Gailenus puer eius advenit. Cumque parvum solatium qui eum ducebat haberent, ab ipso Gaileno in itenere excussus est, opertoque capite indutusque veste saeculari, beati Martini templum expetiit.". Ibidem, V.14.
}

${ }^{39}$ Ibidem, VII.21.

40. Patrick GEARY, Furta Sacra; Thefts of Relics in the Central Middle Ages, Princeton, Princeton University Press, 1990, p. 111.

${ }^{41}$ [...] "Tertia vero nocte postquam advenimus ad sanctam basilicam, vigilare disposuimus; quod inplevimus. Mane autem facto, signo matutinis horis conmonito, reversi fuimus ad metatum. Qui lectulis quiescentes, usque ad horam prope secundam dormivimus. Expergefactus ego, amota omnem languoris et cordis amaritudinem, sentio me praestinam recepisse salutem, et gaudens puerum familiarem, qui mihi serviret, evoco. [...] Tunc ego exultans et flens prae gaudio, gratias omnipotenti Deo tam pro me quam pro ipso refero, quod, intercedente patrono, incolomem me corpore, illum mente reddiderit, et unus occursus ex fide etiam alteri amenti, qui nec petere noverat, praestetisset. Sed nec hoc praeteribo, quod post dies quadraginta eodem die primo vinum delectatus sum bibere, cum illud, faciente incommodo, usque tunc exosum habuerim." En: GREGORIO DE TOURS, Libri I-IV de virtutibus sancti Martini episcopi, I.33. 
Como mencionamos con anterioridad, el otro lugar que contaba con gran relevancia en el reino merovingio era la tumba de Martín de Tours. En la vida del obispo Martín, encontramos varios ejemplos en los que este sepulcro lograba sanar a quienes imploraban la ayuda del santo. Un caso particular es el de Ammonius, quien cumplía funciones religiosas y administrativas en la iglesia de San Martín. Una noche, éste tropezó y cayó por un precipicio, debido a que se hallaba embriagado por el alcohol que bebió mientras cenaba. Durante la caída, imploró a san Martín y logró salvarse. Sólo sufrió una leve herida en uno de sus pies, que sanó después de orar en la iglesia consagrada al santo invocado ${ }^{42}$. En este caso, el milagro no se produce dentro de un recinto sagrado.

Por otro lado, Gregorio de Tours nos cuenta, en el libro segundo de la misma obra, que, al no poder curarse de una fiebre recurriendo a los medios tradicionales, empleó la tierra de este sepulcro para crear una "poción" sanadora. ${ }^{43}$

En otro pasaje, el obispo de Tours recomendaba, en caso de padecer dolores o molestias en alguna parte del cuerpo, tocar la tumba de dicho santo con la parte del cuerpo afectada. Las molestias, afirmaba, desaparecen al instante. ${ }^{44}$ Finalmente, en otro fragmento de esta obra, vemos cómo su autor logró deshacerse de las molestias ocasionadas por una espina de pez atascada en su garganta, nuevamente gracias al poder milagroso de la tumba de Martín de

42 [...] Ammonius quidam agens sanctae basilicae, dum de caena madefactus vino veniret, de excelsa rupe, quae viae coniungitur, inimico inpingente, praecipitatur. [...] Cumque per profunditatem praecipitii illius rotaretur et deorsum sine alarum remigio volitaret, sancti Martini auxilium per singula discensionis suae momenta clamabat. Tunc quasi manibus aliorum de iumento sou excussus, super arbores, quae valli inerant, deicitur. Et sic paulatim per singulos ramos discendens, sine mortis periculo ad terram usque pervenit. Tamen, ut opus insidiatoris non usquequaque videretur cassatum, quod fuerat inchoatum, unum pedem eius leviter laesit. Sed veniens adgloriosi domni templum, orationi incumbens, omnem vim doloris amisit. GREGORIO DE TOURS, op. cit., I.20.

43 "[...] Cumque sic ageretur mecum, ut non remansisset spes vitae, sed concta deputarentur in funere, nec valeret penitus medici antidotum, quem mors mancipaverat ad perdendum, ego ipse de me disperans, vocavi Armentarium archiatrum et dico ei: Omnem ingenium artificii tui inpendisti, pigmentorum omnium vim iam probasti, sed nihil proficit perituro res saeculi. Unum restat quod faciam; magnam tibi tyriacam ostendam. Pulverem de sacratissimo domni sepulchro exhibeant, et exinde mihi facito potionem. Quod si hoc non valuerit, amissa sunt omnia evadendi perfigia. Tunc misso diacono ad antedictum beati praesolis tumulum, de sacrosancto pulvere exhibuit, dilutumque mihi porregunt ad bibendum. Quo hausto, mox omni dolore sedato, sanitatem recipi de tumulo. In quo tam praesens fuit beneficium, ut, cum id actum fuerit hora tertia, incolomis procederem ad convivium ipsa die ad sextam.". Op. cit., II.1.

44 "[...] Testor etenim Deum et spem illam, quam in eius virtute posui, credens, me ab illius misericordia non frustrari; quia, quotienscumque aut dolor capitis inruit, aut timpora pulsus inpulit, aut aures auditus gravavit, aut oculorum aciem caligo suffudit, aut aliis membris dolor insedit, statim ut locum dolentem vel tumulo vel pendente velo adtigi, protinus sanitatem recepi; mirans tacitus, in ipso tactu dolorem recessisse cum cursu". Ibidem, III.Incipit. 
Tours. ${ }^{45}$ Los prelados y religiosos también podían acceder al poder espiritual aun sin estar presentes en lugares sagrados. Tal es el caso del obispo de Orleans, Annianus, quien amparó a los habitantes de la ciudad cuando los hunos se aproximaban para saquearla. Gracias a la oración de este prelado y al convencimiento que logró en los fieles para que continuasen orando, logró salvar la urbe. ${ }^{46}$

Los obispos también ejercían un control lógico sobre el acceso al espacio espiritual. Vulfilaic, un diácono de origen lombardo que se desempeñaba en el monasterio de Yvois, es un ejemplo de esta situación. En el libro VIII de sus historias, Gregorio nos describe la vida de este personaje, destacando su intento de imitar a Simeón de Antioquía al construir una columna y pasar tiempo sobre ella. Además, Vulfilaic llevó a cabo varios milagros con su oración, implorando la ayuda de Martín de Tours ${ }^{47}$. Sin embargo, los obispos le prohibieron continuar con esas prácticas alegando que, al ser un bastardo, no podría ser comparado con Simón de Antioquía y, menos aún, soportar las fatigas propias del lugar. Por estas razones, le recomendaron que abandonase el pilar que construyó y dedicara su tiempo a convivir con sus hermanos. Pese a que la medida no le resultó agradable,

45 "Quid autem nuper pertulerim, primum inseram hic libello miraculum. Dum ad convivium resedentes post ieiunium aederemus, piscis infertur in ferculo, quem dominica cruce signatum dum aedimus, una mihi ex aristis ipsius piscis iniuriosissime adhaesit in gutture. Quae dolores commovens graves, incidebat fauces acumine et ipsam gulam longitudine obserabat; impediebat vocis sonum et neque ipsum salibae liquorem, qui saepe a palato defluit, transire sinebat. Tertia autem die cum neque tussiens neque excreans eam valerem proicere, recurri ad nota praesidia. Accedo ad tumulum, provolvor in pavimento, profusisque cum gemitu lacrimis, auxilium deprecor confessoris. Dehine erectus, velo, qui dependebat, gulam faucesque et reliquum capitis adtigi. Nec mora, sanitatem recepi et, priusquam limina sancta egrederer, nullam fatigationem sensi. Quid tamen aculeus malus devenerit, ignoro. Non eum reieci per vomitum, non discessisse sensi in alvum. Unum tantum scio, quo dita me in velocitate sensi sanatum, ut putarem, quod iniecta aliquis manu illa quae iniuria faucibus intulerant abstulisset.". Op. cit., III.1

${ }^{46}$... Cumque inclusi populi suo pontefice, quid agerent, adclamarent, ille confisus in Deo, monet omnes in oratione prosterni et cum laudacrimis praesentem semper in necessitatibus Domini auxilium implorare. Denique his ut praeciperat depraecantibus, ait sacerdus: 'Aspicite de muro civitatis, si Dei miseatio iam succurrat'. Suspicabatur enim per Domini misericordiam Aetium advenire, ad quem et Arelate abierat prius suspectus futuri. Aspicientes autem de muro, niminem viderunt. Et ille: 'Orate', inquid, 'fideliter; Dominus enim liberavit vos hodie!' Orantibus autem illis, ait: 'Aspicite iterum!'. Et cum aspexissent, niminem viderunt qui ferret auxilium. Ait ies tertio: 'Si fideliter petitis, Dominus velociter adest'. Ad ille cum fletu et heiulatu magno Domini misericordiam inplorabant. Exactam quoque orationem, tertio iuxta senis imperium aspicientes de muro, viderunt a longue quasi nebolam de terra consurgere. Quod renuntiantes, ait sacerdus: 'Domini auxilium est'. Interea iam trementibus ab impetu arietum muris iamque ruituris, ecce! Aetius etTheudor Gothorum rex ac Thorismodus, filius eius, cum exercitibus suis ad civitatem adcurrunt adversumque hostem eieciunt repelluntque. Itaque liberatam obtentu beati antestites civitatem, Attilanem fugant. Qui Mauriacum campum adiens, et praecingit ad bellum. Quod hi audiens, se contra eum viriliter praeparant". GREGORIO DE TOURS, Libri Historiarum X., II.7.

${ }^{47}$ GREGORIO DE TOURS, Libri Historiarum X., VIII.15.

\section{4}


aun así decidió cumplir con la misma, debido a que no deseaba ser llamado "desobediente".

El caso resulta interesante debido a que, en él, podemos encontrar un ejemplo sobre cómo los obispos controlaban la administración de la práctica espiritual, prohibiendo su acceso a aquellos que podían constituir un peligro para su clase, como Vulfilaic. Éste, al haber sido un diácono carismático, logró convertir al cristianismo a muchos que anteriormente habían sido devotos de Diana. También había llevado a cabo milagros y su influencia sobre la comunidad era grande. Sin embargo, el cuerpo episcopal vio en su figura una seria amenaza, que podría llegar a arrebatarle el control de la estructura espiritual en el futuro.

A raíz de los ejemplos que hemos citado, todo parece indicar que los obispos se consideraban los únicos capaces de administrar el orden espiritual y se erigían como monopolizadores de lo sagrado. En la mayoría de los casos, además, son los prelados quienes lograban entrar en contacto con la manifestación del poder divino a través de los milagros.

\section{El siglo VII y su contexto religioso y social}

Durante el siglo VII cobró gran importancia la combinación de las reglas monásticas benedictinas y columbanas, la cual influyó sobre parte de la elite franca. Esto trajo grandes cambios con respecto a la organización episcopal y a la manera en la cual el cristianismo se estaba difundiendo hasta el momento ${ }^{48}$. De ahora en más, estos aristócratas de origen franco pasarían a desempeñar un papel religioso y social de mayor importancia en el norte de la Galia.

Con el afianzamiento de los obispados a partir del siglo VII, muchos de los miembros de esta estirpe proveniente del norte, comenzaron a donar tierras a la Iglesia para la fundación de monasterios ${ }^{49}$. Además, esto reforzó la influencia católica en las familias de la aristocracia franca, muchos de cuyos donadores habrían de ser canonizados con posterioridad. Dichas familias, de tal manera, lograban adquirir un prestigio y un reconocimiento más elevado. Numerosos

\footnotetext{
${ }^{48}$ Antes de que estos cambios tuviesen lugar, por lo general, los miembros de la aristocracia franca -a diferencia de su par galo-romana del sur- no participaban en el ámbito episcopal. Para los aristócratas francos, recibir la dignidad de obispo significaba, entre otras cosas, adoptar los rasgos y tradiciones socioculturales pertenecientes a la aristocracia senatorial del sur de la Galia.

${ }^{49}$ Los cuales se convertirían en importantes centros espirituales para las pequeñas unidades territoriales de control familiar.
} 
hombres serían entonces canonizados luego de su muerte por haber contribuido con la expansión de la actividad religiosa a lo largo de los siglos VI y VII.

La importancia de estas transformaciones reside en que el orden espiritual, con el tiempo, comenzaría a ser administrado en mayor grado por los francos, con lo cual se aceleraría el proceso de cristianización en las áreas rurales. Asimismo, esto trajo otra consecuencia: el acaparamiento exclusivo de las funciones episcopales ya no se encontraría solamente en manos de la aristocracia galoromana. A partir del siglo VII, los aristócratas francos no sólo se encargarían de la labor religiosa propia del obispo -brindando ayuda a los necesitados y administrando propiedades eclesiásticas- sino que, además, darían comienzo a la expansión de su tutela sobre el mundo espiritual a través de las donaciones de tierras destinadas a la construcción de monasterios y capillas. Pero también es importante señalar que participarían activamente en este proceso a través de la canonización de los miembros de sus familias, es decir, aquellos que donaron dichas tierras o comenzaron con la construcción de las edificaciones destinadas a la iglesia ${ }^{50}$.

\section{Los obispos y la política en el siglo VII}

Ahora bien, de la misma manera que sus pares galo-romanos, los obispos de origen franco también se involucraron en la política del reino, incluso en el desempeño de funciones propias de carácter político. Un ejemplo de esta situación lo constituye Arnulfo, quien fue obispo de Metz durante la primera mitad del siglo VII. La crónica de Fredegario nos cuenta que, pasados tres días de la boda de Dagoberto con Gomatruda, una disputa tuvo lugar entre aquél y su padre, el rey Clotario II, por una serie de territorios en pugna.

Elictis ab his doubus regibus duodicem Francis, ut eorum disceptatione hace finirit intentio, inter quos et domnus Arnulfus pontifex Mettensis cum reliquis episcopis elegitur et benignissime, ut sua erat sanctitas, inter patrem et filium pro pacis loquebatur concordia, tandem a pontificebus vel sapientissimis viris procerebus pater paceficatur cum filio. Reddensque ei soledatum quod aspexerat ad regnum Austrasiorum, hoc tantum exinde, quod citra Legere vel Provinciae partibus situm erat, suae dicione retenuit. ${ }^{51}$

\footnotetext{
${ }^{50}$ También fueron canonizados aquellos miembros pertenecientes a las familias donantes que se desempeñaron como los primeros abades y abadesas de estos monasterios. Lógicamente, esto añadía a tales familias una tradición de poder sobrenatural y prestigio: P. GEARY, op. cit., p. 173.

51 FREDEGARII ET ALIORUM CHRONICA. VITAE SANCTORUM, MGH SRM II, ed. Bruno Krusch, Hanover, 1888, IV.53.
} 
Resulta sorprendente que, entre los doce francos elegidos por los dos reyes para saldar la disputa, se encontraran tanto el mencionado obispo Arnulfo, como así también otros prelados. En este fragmento, la crónica no hace referencia sobre la identidad de los otros francos que integraban la comisión; solamente menciona a los obispos. Si tenemos en cuenta que Fredegario, el autor de este controvertido texto ${ }^{52}$, habría sido un sacerdote, esto podría ser interpretado como un modo de resaltar el poder y la importancia que poseía la institución episcopal, subrayando las funciones que debían cumplir para con los monarcas merovingios. De tal manera, la trascendencia de estos funcionarios llegaba al punto de que los mismos podían ser convocados para resolver una disputa entre dos soberanos, como lo describe el pasaje citado.

La misma fuente nos da a entender, además, que los miembros del episcopado franco también debían aconsejar al rey en situaciones de guerra con otros pueblos. Esto lo vemos, por ejemplo, cuando el rey Dagoberto se enteró de que Samo estaba atacando los territorios cercanos a la frontera con sus tropas eslavas. El entonces monarca organizó una reunión en la ciudad de Metz para pedir ayuda y consejo, tanto a los nobles francos como así también a los obispos. ${ }^{53}$

Además, también en el siglo VII, los obispos se encargaban de ejercer funciones vinculadas al gobierno terrenal. En la continuación del pasaje citado anteriormente hallamos un caso muy importante en lo que respecta a este apartado: "...Chunibertum Coloniae urbis pontevecem et Adalgyselum ducem palacium et regnum gobernandum instetuit". ${ }^{54}$

Este caso resulta muy notorio debido a que Dagoberto dejó el gobierno del palacio y del reino en manos de Cuniberto, el obispo de Colonia, y del duque

\footnotetext{
${ }^{52}$ La Crónica de Fredegario es la única fuente escrita que fue compuesta en el siglo VII en la Galia merovingia. El contenido de la obra consiste en una sucesión de acontecimientos políticos que tuvieron lugar en el reino merovingio durante la primera mitad de dicho siglo. Debido a esto, el texto posee gran importancia. Sin embargo, la obra presenta una serie de problemas historiográficos, sobre todo en lo que respecta a la identidad de su autor y el desconocimiento de las fuentes que el mismo utilizó para su elaboración. Para este tema, véase entre otros trabajos: Magali COUMERT, Origines des Peuples; Les Récits du Haut Moyen Âge Occidental (550-850), Paris, Institut d'Études Augustiniennes, 2007, pp. 295-297; John Michael WALLACE-HADRILL (trad.), The Fourth Book of the Chronicle of Fredegar with its Continuations, Connecticut, Greenwood Press, 1960.
}

53 "Anno undecimo regni Dagoberti, cum Winidi iusso Samone forteter servint et sepius, transcesso eorum limite, regnum Francorum vastandum Toringia et relequos pagus ingrederint, Dagobertus Mettis orbem veniens, cum consilio pontevecum seo et procerum, omnesque primatis regni sui consencientebus...". En: FREDEGARII ET ALIORUM CHRONICA. VITAE SANCTORUM, op. cit., IV.75.

54 Ibidem.

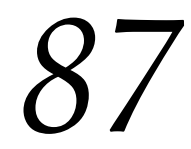


Adalgisel. El poder fue repartido entre un funcionario civil y uno religioso. Esto nos demuestra que, hacia el siglo VII, los reyes francos habrían necesitado en gran medida las habilidades administrativas de los obispos al punto de encargarles el cuidado de un reino y de un palacio, junto a un administrador civil.

El resto de la crónica describe situaciones en las cuales los obispos están presentes en reuniones o asambleas junto con los aristócratas francos, ya sea para la designación de algún funcionario, como para tratar asuntos importantes en lo que respecta al gobierno civil. Esto lo vemos, por ejemplo, cuando se reunieron en Clichy para tratar el asesinato de Ermarius, un hombre que prestaba servicios a Chariberto II, el hijo del rey Clotario II. ${ }^{55}$ Nuevamente se habían reunido tras la muerte de este último, para presentar su lealtad a su hijo Dagoberto. ${ }^{56}$ Se congregaron en otra asamblea luego del nacimiento de Clovis, el hijo de Dagoberto y Nantechilda, con el objetivo de establecer cuáles serían los territorios que pasarían a su dominio tras la muerte de su padre. ${ }^{57}$ Finalmente, un gran cónclave tuvo lugar en Orleans, donde la reina Nantechilda nombró mayordomo

\footnotetext{
55 "Anno 44. regni Chlotariae cum pontificis et universi proceres regni sui tam de Neuster quam de Burgundia Clippiaco ad Clotharium pro utilitate regia et salute patriae coniuncxissent, ibique homo nomen Ermarius, qui gobernatur palatiae Gairiberto, filio Chlothario, erat, a pueris Aeghynanae genere Saxonorum optimate interficetur...". Op. cit., IV.55.

56 "Anno 46. regni sui Chlotharius moritur et suburbano Parisius in ecclesia sancti Vincenti sepellitur. Dagobertus cernens genitorem suum fuisse defunctum, universis leudibus, quos regebat in Auster, iobet in exercito promovere. Missus in Burgundia et Neuster direxit, ut suum deberint regimen eligere. Cumque Remus venisset, Soissionas peraccedens, omnes pontefecis et leudis de regnum Burgundiae inibi se tradedisse nuscuntur; sed et Neustrasiae pontefecis et proceres plurima pars regnum Dagoberti visi sunt expetisse. Airibertus frater suos nitibatur, si potuisset, regnum adsumeret; sed eius voluntas pro simplicitate parum sortitur effectum. Brodulfus vellens nepotem estabilire in regnum, adversus Dagoberto muscipulare coeperat; sed huius rei vicissitudinem probavit aeventus.". Op. cit., IV.56.

57 "Cumque anno duodecemo regni Dagoberti eidem filius nomen Chlodoveos de Nanthilde regina natus fuissit, consilio Neustrasiorum eorumque admonicione per pactiones vincolum cum Sigybertum, filium suum, firmasse dinuscetur, et Austrasiorum omnes primati, pontevecis citirique leudis Sigyberti manus eorum ponentes insuper, sacramentis firmaverunt, ut Neptreco et Burgundia soledato ordene ad regnum Chlodoviae post Dagoberti discessum aspecerit; Aoster vero idemque ordine soledato, eo quod et de populo et de spacium terre esset quoaequans, ad regnum Sigyberti idemque in integretate deberit aspecere; et quicquid ad regnum Aostrasiorum iam olem pertenerat, hoc Sigybertus rex suae dicione rigendum recipere et perpetuo dominandum haberit, excepto docato Dentilini, quod ab Austrasius iniquiter abtulus fuerat, iterum ad Neustrasius subiungeretur et Chlodoveo regimene subgiceretur. Sed has pacciones Austrasiae, terrorem Dagoberti quoacti, vellint nonlint, firmasse visi sunt. Quod postea temporebus Sigyberti et Chlodoviae regibus conservatum fuisse constat". Op. cit., IV.76.
} 
de palacio a Flaogatum, tras la aprobación de todos los obispos y aristócratas francos. ${ }^{58}$

A partir de los ejemplos citados de la crónica de Fredegario, podemos decir que, durante el siglo VII, los obispos cumplieron un papel de mayor importancia en lo concerniente a la política. Cabe destacar que el libro IV de esta fuente -que se dedica a los acontecimientos de la primera mitad del siglo VII-, a diferencia de los Decem Libri Historiarum, no describe ninguna situación en la que los obispos difuntos o los santos en su conjunto realicen milagros o exorcismos, es decir, atribuciones propias referidas al orden espiritual. Tampoco menciona la fundación de iglesias o parroquias. Asimismo, no hace referencia a las iglesias como lugares importantes o sitios donde refugiarse, ni se encarga de detallar la sucesión de personas que ocuparon la dignidad episcopal ni los mecanismos de selección. A causa de estas características, da la sensación de que su autor habría deseado concentrarse más en los sucesos puramente políticos que en los de carácter espiritual o religiosos, restándole importancia a estos últimos. Esto resulta interesante ya que explicita, de forma manifiesta, las funciones políticas y públicas que estos administradores desempeñaban en la sociedad franca de la época.

\section{Los concilios francos}

Como lo indica el título de este apartado, las reuniones llevadas a cabo en el marco de los concilios francos representaban uno de los aspectos más importantes de la institución episcopal. En dichas reuniones, sus miembros trataban temas de diversa índole. Gregory Halfond define a esas asambleas como:

[...] meetings held among the church leadership, either on the diocesan, provincial, interprovincial, or ecumenical level. They could be convoked by secular and ecclesiastical leaders alike, and were attended by a mix of bishops, clerics, monks, and occasionally laymen, depending on the geographic representation and agenda of the meeting [...] The agendas of these councils were usually multifaceted. One important task, particularly at

\footnotetext{
58 "Anno quarto regni Chlodoviae, eumque Nantildis regina cum filio suo Chlodovio regi post discessum Aeganem Aurilianes in Burdiae regnum venissit, ibique omnes seniores, ponteveces, ducebus et primatis de regnum Burgundiae ad se vinire precepit. Ibique cumtus Nantildis sigillatem adtragens, Flaogatum genere Franco maiorem domus in regnum Burgundiae selectionem pontevecum et cumtis docebus a Nantilde regina hoc gradum honores stabilitur, neptemque suam nomini Ragnoberta Floachadum disponsavit.". Op. cit., IV.89.
} 
the larger meetings, was the composition of ecclesiastical legislation. Through the course of deliberation, the attendees produced a series of decisions known as canones, which are intended to define the rules of church life..$^{59}$

Un aspecto a destacar en estos encuentros es la influencia secular ${ }^{60}$ que los mismos tuvieron en este período, influencia que perduraría incluso hasta fines del período carolingio. Un ejemplo de esta situación es el primer concilio que tuvo lugar en el Regnum Francorum ${ }^{61}$, convocado por el rey Clovis cuatro años después de la batalla de Vouillé62. A menudo, los soberanos merovingios participaban en estos concilios, por lo general, convocándolos. ${ }^{63}$

En el libro IX de sus historias, Gregorio nos cuenta cómo el rey Gontrán ordenó a su sobrino Childeberto convocar un gran sínodo debido a que hay demasiadas cosas para ser tratadas. ${ }^{64}$ El propio Gregorio, al preguntar cuál era el

${ }^{59}$ Gregory I. HALFOND, The Archaeology of Frankish Church Counsils AD 511-768, Leiden, Brill, 2010, p. 8.

${ }^{60}$ Halfond destaca este rasgo como característicos de los concilios francos y afirma que no es sorprendente que en los mismos hayan participado laicos, teniendo en cuenta el origen aristocrático y civil de los obispos.

${ }^{61} \mathrm{Si}$ bien el Concilio de Orleans del año 511 fue el primero en ser convocado por un rey franco, desde el siglo IV se llevaron a cabo numerosos concilios en la Galia, muchos de los cuales fueron organizados por emperadores romanos, es decir, por la autoridad civil. La práctica de permitir la participación de un gobernante terrenal comenzó con Constantino I, quién presidió el Concilio Ecuménico de Nicea del año 325. Halfond sostiene que esta práctica (que también fue adoptada por los francos) no fue más que un ejemplo de la imitatio imperii y que, al hacerlo, Clovis estaba participando en una institución cuyas raíces se hundían profundamente en las costumbres galoromanas.

${ }^{62}$ La batalla en la cual el rey visigodo Alarico II fue muerto a manos del mismo Clovis, según nos cuenta Gregorio de Tours. En: GREGORIO DE TOURS, Libri Historiarum X, II.37.

${ }^{63}$ En un pasaje de los Libri Historiarum, el Rey Gontrán I convoca un sínodo tras enterarse de los crímenes cometidos por los obispos Salunius y Sagittarius. "Igitur contra Salonium Sagittariumque episcopos tumultus exoritur. Hi enim a sancto Nicetio Lugdunensi episcopo educati, diaconatus officio sunt sortiti; huiusque tempore Salonius Ebredunensis urbis, Sagittarius autem Vappinsis ecclesiae sacerdotes statuuntur. Sed, adsumpto episcopatu in propio relati arbitrio, coeperunt in pervasionibus, caedibus, homicidiis, adulteriis diversique in sceleribus insano furore crassari, ita ut quodam tempore, celebrante Victore Tricassinorum episcopo sollemnitatem natalicii sui, emissa cohorte, cum gladiis et sagittis inruerent super eum. Venientesque sciderunt vestimenta eius, ministros ceciderunt, vasa vel omne apparatum prandii auferentes, relinquentes episcopum in grandi contumelia. Quod cum rex Guntchramnus comperisset, congregari synodum apud urbem Lugdunensim issuit. Coniunctique episcopi cum patriarcha Nicetio beato, discussis causis, invenerunt eos de his miserant episcopatus honore privarentur." Op. cit., V.20.

64 "...Indecastis enim nepoti vestro, ut omnes regni sui episcopi in unum convenirent, quia multa sunt, quae debeant indegare". 
motivo por el que debía ser llevada a cabo tamaña reunión, obtuvo la siguiente respuesta:

Sunt multa, inquid, quae debeant discerni, quae iniuste gesta sunt, tam de incestis quam de ipsis quae inter nos aguntur causis. Sed praecipue illa Dei causa extat omnibus maior, ut inquerere debeatis, cur Praetextatus episcopus gladio in aeclesia fuerit interemptus. Sed et de his, qui pro luxoriam accusantur debet esse discussio, ut aut victi sanctione sacerdotali debeant emendari aut certe, si innocentes inveniuntur, publice error criminis auferatur. ${ }^{65}$

No debe sorprendernos que, durante esta etapa, un monarca se preocupase por las cosas de Dios, además del asesinato de un obispo, junto con aquellas cuestiones que estaban más vinculadas con la vigilancia de la Iglesia. Dicha preocupación es propia del contexto político, social y cultural en que se desarrolló el reino merovingio. Sin embargo, esta tradición -en virtud de la cual las autoridades civiles se involucraban en los asuntos de la religión católica- no era enteramente nueva. La misma se inició con el emperador Constantino quien, además de haberse declarado "obispo de aquellos que están afuera", incentivó a los aristócratas a convertirse al cristianismo, mediante la concesión de numerosos privilegios. ${ }^{66}$

La influencia secular también estaba presente en lo que respecta a los cánones, los cuales, en ocasiones, eran tomados como base a la hora de generar nuevas legislaciones civiles. Además, los monarcas emitían concesiones y privilegios a fundaciones clericales y monásticas, debiendo éstas ser confirmadas durante los concilios. ${ }^{67}$

Del análisis realizado, podemos decir que la institución de los concilios francos, al menos durante el siglo VI, fue una institución de carácter religioso. Sin embargo, dicha institución se encontraba en la confluencia de una doble dimensión temporal-espiritual, es decir, poseía atribuciones laicas y religiosas. Además, los concilios presentaban otro rasgo de carácter secular: la acción política

\footnotetext{
${ }^{65}$ GREGORIO DE TOURS, op. cit., IX.20.

${ }^{66}$ Para un análisis detallado acerca de cómo influyó la figura del emperador en la adopción del cristianismo por parte de la aristocracia romana, véase: Michele SALZMAN, The Making of a Christian Aristocracy; Social and Religious Change in the Western Roman Empire, Cambridge, Hardvard University Press, 2004, pp. 178-199.
}

${ }^{67}$ Gregory I. HALFOND, op.cit., p. 13. 
de los reyes merovingios. Éstos participaban activamente en tales reuniones guiados por fines específicos: los obispos congregados eran los encargados de elaborar leyes y normas con el objetivo de optimizar el gobierno y la administración del reino.

El hecho de que los soberanos merovingios empleasen a estos personajes en tales tareas nos demuestra la importancia que los mismos poseían debido a que, por lo general, eran las únicas personas que contaban con la formación requerida para cumplir estas funciones político-administrativas. Tal recurso, también forma parte de una tradición que se generó en los siglos IV y V. ${ }^{68}$ Como vemos, los monarcas merovingios tomaron como modelo las medidas implementadas por los emperadores que favorecieron la expansión del cristianismo (Constantino, Constancio II, Graciano y Teodosio). A partir de ellos, los miembros del episcopado servían al emperador llevando a cabo tareas correspondientes a diversos cargos administrativos. ${ }^{69}$

\section{Consideraciones finales}

De todo lo expuesto, podemos decir que, en la Francia merovingia de los siglos VI y VII, existía una fusión de los espacios civil y religioso. La misma se manifestaba en diversas ocasiones: en las interrelaciones que se producían entre la institución episcopal y las autoridades políticas del momento (es decir, los reyes merovingios) y en las funciones que cumplían los obispos en el ámbito laico, siendo las mismas muy similares a las de los gobernadores y funcionarios romanos.

En la mayoría de los casos, los obispos de la Galia contaban con antecedentes aristocráticos y lograban acceder a la dignidad de obispo luego de atravesar por un cursus honorum en la administración civil, sin la necesidad de pasar por los escalafones de la carrera eclesiástica. Por ejemplo, funcionarios tales como los mayordomos de palacio, podían alcanzar la dignidad episcopal. Si bien esta modalidad data de los tiempos tardoimperiales, la misma se intensificó

\footnotetext{
${ }^{68}$ Michele SALZMAN, op. cit., pp. 200-219.

${ }^{69}$ También es posible hallar una similitud con el modelo implementado por Justiniano en el siglo VI. En tal modelo, los obispos eran los representantes directos del emperador en las provincias y debían velar por el correcto funcionamiento de la estructura fiscal y administrativa.
} 
durante las últimas décadas de existencia del Imperio Romano de Occidente e, incluso, durante el reino merovingio temprano.

Durante esta etapa, los prelados se desempeñaban en funciones civiles y políticas. Los mismos debían asistir a reuniones junto con el monarca merovingio y otros aristócratas francos a fin de asesorar al soberano en sus decisiones. Además, los miembros del episcopado se entendían como los únicos capacitados para regular el poder espiritual y con ello, su administración exclusiva era su prerrogativa.

Finalmente, los reyes merovingios poseían gran autoridad a la hora de decidir quién reemplazaría a un obispo difunto. Si bien los obispos del reino se reunían para elegir un candidato determinado, la decisión final la tomaba el monarca sin importar aquello que acordaban los miembros del episcopado. 